\title{
En bloc rotation of the truncus arteriosus-an option for anatomic repair of transposition of the great arteries, ventricular septal defect, and left ventricular outflow tract obstruction
}

\author{
Rudolf Mair, MD, ${ }^{a}$ Eva Sames-Dolzer, MD, ${ }^{\text {a }}$ David Vondrys, MD, ${ }^{a}$ Evelyn Lechner, MD, ${ }^{b}$ \\ and Gerald Tulzer, MD, PhD, ${ }^{\mathrm{b}}$ Linz, Austria
}

$\mathrm{T}$ he classic repair in transposition of great arteries/ ventricular septal defect/left ventricular outflow tract obstruction (TGA/VSD/LVOTO) or double-outlet right ventricle/ transposition of great arteries/left ventricular outflow tract obstruction (DORV/TGA/LVOTO) is a Rastelli procedure. ${ }^{1}$ Its long-term problems are widely known: A long intracardiac tunnel frequently leads to subaortic obstruction, and a homograft or xenograft in pulmonary position has to be changed several times. Réparation à l'étage ventriculaire ${ }^{2}$ decreases but does not solve these problems. Aortic translocation ${ }^{3}$ and the RossKonno switch operation ${ }^{4}$ move the aorta back over the LVOT and avoid a long intracardiac tunnel.

Dr Yamagishi recently reported a case of en bloc rotation of the truncus arteriosus, ${ }^{5}$ bringing the aortic root over the LVOT and the pulmonary root over the right ventricular outflow tract (RVOT).

In these malformations obstruction of the LVOT frequently is predominantly subvalvular, and the pulmonary valve, although small in size, may be appropriate for the RVOT. Sometimes simple surgical maneuvers at the level of the valve can make this possible so that, in these cases, a complete anatomic repair with autologous material can be achieved.

\section{Patients}

Since July 2003, 3 patients underwent en bloc rotation of the truncus arteriosus at our center (Table 1). In all 3 patients the obstruction of the LVOT was subvalvular, and the pulmonary valve was bicuspid (Table 2). Patient 1 had undergone 4 palliative operations before he was referred to us: atrioseptectomy, right modified Blalock-Taussig shunt, bidirectional Glenn, and right-sided Glenn. In patients 2 and 3 , rotation of the truncus arteriosus was the primary repair.

\section{Operative Technique}

The aorta is divided well above the coronary ostia. The latter are excised and mobilized as in an arterial switch procedure. The

\footnotetext{
From the Department of Cardiac Surgery, General Hospital Linz, ${ }^{\mathrm{a}}$ and the Department of Pediatric Cardiology, Children's Hospital Linz, ${ }^{\mathrm{b}}$ Austria.

Received for publication Oct 13, 2005; accepted for publication Oct 24, 2005.

Address for reprints: Rudolf Mair, MD, Department of Cardiac Surgery, General Hospital Linz, Krankenhausstr 9, A-4020 Linz, Austria (E-mail: rudolf.mair@akh.linz.at).

J Thorac Cardiovasc Surg 2006;131:740-1

$0022-5223 / \$ 32.00$

Copyright $\odot 2006$ by The American Association for Thoracic Surgery doi:10.1016/j.jtcvs.2005.10.047
}

\section{TABLE 1. Patients}

\begin{tabular}{cccccc}
\hline No. & Gender & Age & Weight & Height & Anatomy \\
\hline 1 & Male & $5 \mathrm{y}$ & $18.8 \mathrm{~kg}$ & $115 \mathrm{~cm}$ & $\begin{array}{l}\text { DORV/TGA, } \\
\text { subpulmonary VSD, } \\
\text { LVOT obstruction }\end{array}$ \\
2 & Female & $1 \mathrm{y} 4 \mathrm{~d}$ & $5.9 \mathrm{~kg}$ & $60 \mathrm{~cm}$ & $\begin{array}{l}\text { TGA, subpulmonary VSD, } \\
\text { LVOT obstruction }\end{array}$ \\
3 & Male & $8 \mathrm{~d}$ & $3.5 \mathrm{~kg}$ & $51 \mathrm{~cm}$ & $\begin{array}{l}\text { TGA, subpulmonary VSD, } \\
\text { LVOT obstruction }\end{array}$ \\
\hline
\end{tabular}

DORV, Double outlet right ventricle; $L V O T$, left ventricular outflow tract; $T G A$, transposition of great arteries; $V S D$, ventricular septal defect.

TABLE 2. Echocardiographic data

\begin{tabular}{cccc}
\hline Patient no. & $\begin{array}{c}\text { Pulmonary } \\
\text { valve diameter }\end{array}$ & $\begin{array}{c}\text { LVOT } \\
\text { diameter }\end{array}$ & $\begin{array}{c}\text { Aortic valve } \\
\text { diameter }\end{array}$ \\
\hline 1 & $15.3 \mathrm{~mm}$ & $8 \mathrm{~mm}$ & $16.9 \mathrm{~mm}$ \\
2 & $10 \mathrm{~mm}$ & $4 \mathrm{~mm}$ & $17 \mathrm{~mm}$ \\
3 & $6 \mathrm{~mm}$ & $3.6 \mathrm{~mm}$ & $10 \mathrm{~mm}$ \\
\hline
\end{tabular}

LVOT, Left ventricular outflow tract.

pulmonary artery is divided at the same height (Figure 1), and the pulmonary valve is inspected and sized with Hegar dilators.

A transverse incision is made into the subaortic conus (Figure $1, A)$, and the truncus arteriosus including the subarterial part of the conus septum is excised en bloc. The residual part of the conus septum is transected (Figure $1, B$ ). The papillary muscle of the conus must be spared.

The VSD is closed by a U-formed pericardial patch, thus enlarging the LVOT.

The truncus block is rotated by $180^{\circ}$ and reimplanted, so the aortic root is brought over the LVOT, and the pulmonary root over the RVOT (Figure 1, C). The coronaries are reconnected to the aorta, and a Lecompte maneuver is performed.

Patch enlargement of the RVOT was necessary in all 3 cases.

In patient 1 , bilateral commissurotomy of the pulmonary valve was performed as well as a Glenn takedown and a pulmonary artery reconstruction. Cardiopulmonary bypass time ranged between 263 and 360 minutes; aortic crossclamp time ranged between 142 and 161 minutes.

\section{Results}

All patients survived the procedure. In patient 3 (a neonate), the chest was left open for 2 days because of capillary leakage and 
A

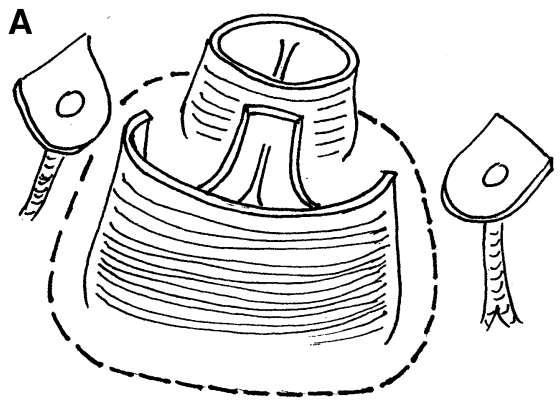

B

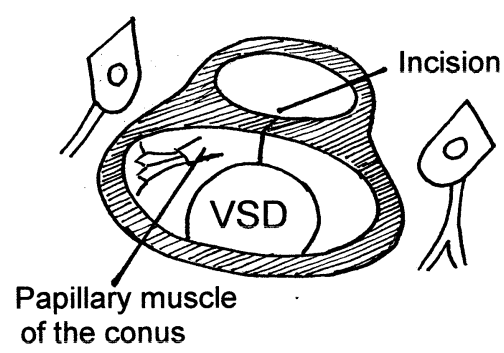

C

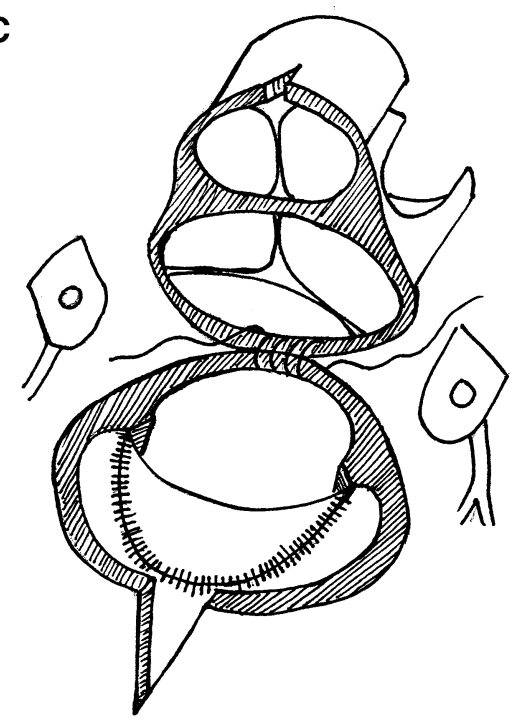

Figure 1. A, En bloc excision of the truncus arteriosus (dotted line). B, Incision of the conus septum. C, Reimplantation of the truncus arteriosus after rotation by $180^{\circ}$. mediastinal edema. The patients were out of the intensive care unit within 3 to 7 days and were discharged from the hospital after 12 to 31 days. No neurologic deficit was seen.

Flow in the LVOT was unobstructed and was laminar in all patients. The pulmonary valve was competent in all cases. Although flow in the RVOT and across the pulmonary valve was laminar, flow velocity was increased to 2 respectively $2.5 \mathrm{~m} / \mathrm{s}$, and a gradient between 16 and $25 \mathrm{~mm} \mathrm{Hg}$ was calculated.

In patient 1 , the gradient across the pulmonary valve decreased within 1.5 years from $25 \mathrm{~mm} \mathrm{Hg}$ to $16 \mathrm{~mm} \mathrm{Hg}$. Patient 2, who was referred to us by a human aid organization, unfortunately was lost to follow-up. In patient 3, there is no gradient in the RVOT and across the pulmonary valve, but an increased flow velocity of $3 \mathrm{~m} / \mathrm{s}$ was measured at the distal pulmonary anastomosis at the age of 8 months.

\section{Discussion and Conclusions}

In contrast to the Rastelli procedure and the réparation à l'étage ventriculaire, a long intracardiac tunnel is avoided by en bloc rotation of the truncus arteriosus. After rotation the aorta is directly over the LVOT, which is enlarged by the VSD patch and, therefore, unobstructed. In contrast to Dr Yamagishi's first reported case, ${ }^{5}$ the pulmonary valves of our 3 patients could be kept intact, requiring only that we either enlarge the subpulmonary region or do a commissurotomy. The resulting gradient was low and decreased in 1 patient during follow-up.

En bloc rotation of the truncus arteriosus is an excellent option for complete anatomic repair in TGA/VSD and LVOT obstruction, or DORV/TGA and LVOT obstruction. At least in selected cases, the patient's own pulmonary valve, although bicuspid or asymmetric, is appropriate for the position in the RVOT. Thus, a complete anatomic repair with competent valves and growth potential in all its tubular structures can be achieved.

\section{References}

1. Rastelli GC, Wallace RB, Ongley PA. Complete repair of transpostion of the great arteries with pulmonary stenosis. Circulation. 1969;39:83-95.

2. Lecompte Y, Neveux JY, Leca F, Zannini L, Tu TV, Dubois Y, et al. Reconstruction of the pulmonary outflow tract without prosthetic conduit. J Thorac Cardiovasc Surg. 1982;84:727-33.

3. Nikaidoh $\mathrm{H}$. Aortic translocation and biventricular outflow tract reconstruction. J Thorac Cardiovasc Surg. 1984;88:365-72.

4. Haas GS. Advances in pediatric cardiovascular surgery: anatomic reconstruction of the left ventricular outflow tract in transposition of the great arteries with pulmonic valve abnormalities. Curr Opinion Pediatr. 2000;12:501-4.

5. Yamagishi M, Shuntoh K, Matsushita T, Fujiwara K, Shinkawa T, Miyazaki T, et al. Half-turned truncal switch operation for complete transposition of the great arteries with ventricular septal defect and pulmonary stenosis. J Thorac Cardiovasc Surg. 2003;125:966-8. 